\title{
Acute small bowel obstruction due to chicken bone bezoar
}

This article was published in the following Dove Press journal:

International Medical Case Reports Journal

3 December 2012

Number of times this article has been viewed

\section{Preadeepan Vetpillai' \\ Ayo Oshowo 2}

'CT2 Surgery in General, Charing Cross Hospital, ${ }^{2}$ Colorectal and Laparoscopic Surgery, Whittington Hospital, London, UK
Correspondence: Preadeepan Vetpillai CT2 Surgery in General, Charing Cross Hospital, Fulham Palace Road, London W6 8RF, UK

Email pvetpillai@yahoo.co.uk
Abstract: Acute intestinal obstruction due to foreign bodies, or bezoar, is a rare occurrence in an adult with a normal intestinal tract. We report an unusual case of a 43 -year-old black man with no previous abdominal surgery and no significant medical history who presented with an acute episode of small bowel obstruction due to an impacted undigested chicken bone.

Keywords: small bowel obstruction, chicken bone, bezoar

\section{Introduction}

Although bowel perforation due to ingested bone is well documented, only two case reports of small bowel obstruction related to ingested bone exist in the literature. ${ }^{1,2}$ To our knowledge, this case is the first to report acute small bowel obstruction occurring in a normal gastrointestinal tract, free from adhesions and previous surgery. This report serves as a useful reminder to surgeons of the potential devastating effect of bezoar and highlights how a recent dietary history may confer clues to the etiology of bowel obstruction.

\section{Case report}

A 43-year-old black man with no past medical history was admitted with 3 days of progressively worsening, cramping lower abdominal pain, distension, and non-bilious vomiting. He had no history of previous abdominal surgery. Seventy-two hours prior to presentation, he had consumed a large meal of fried chicken. He denied being under the influence of alcohol during this meal and explained that he habitually chews and ingests chicken bone. He had no history of mental health problems and no history of alcoholism.

On inspection, the abdomen was markedly distended. Palpation revealed a tense abdomen and mild diffuse tenderness to deep palpation. Tympanic bowel sounds were present on auscultation. The rectum was empty and not ballooned. There was no evidence of hernia.

Abdominal X-ray illustrated multiple dilated small bowel loops with the largest dilation measuring $3.9 \mathrm{~cm}$ transversely (Figure 1). Contrast-enhanced computed tomography (CT) of the abdomen demonstrated multiple loops of dilated, gas- and fluid-filled small bowel measuring up to $4.5 \mathrm{~cm}$ with high density material in the terminal ileum (Figure 2). There was no free intraperitoneal air. The decision was made to perform a laparotomy for acute intestinal obstruction. This revealed an ischemic terminal ileum with impending perforation. The terminal ileum was completely obstructed with impacted small black granules resembling gravel. No adhesions were found. The bowel 


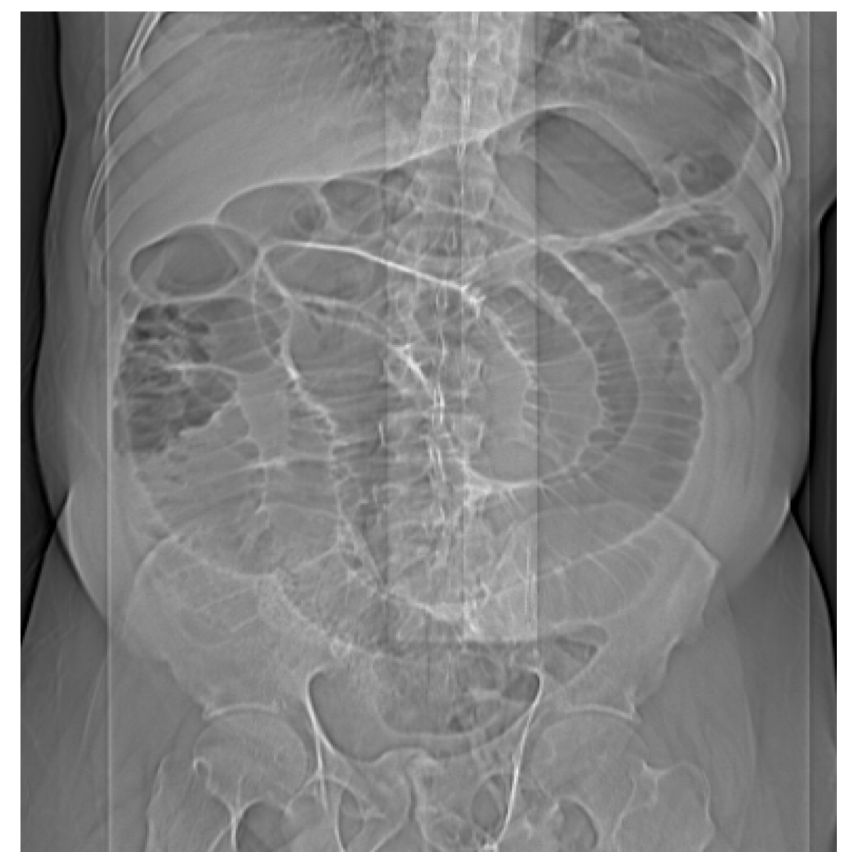

Figure I Abdominal X-ray revealing multiple, dilated small bowel loops.

was decompressed and an ileocecal resection was performed with a primary end-to-end anastamosis.

Histological analysis of the extracted black granules revealed impacted, spiculated, undigested, devitalised bone.

\section{Discussion}

A bezoar is an accumulation of ingested foreign material found anywhere along the gastrointestinal system but most commonly in the stomach. ${ }^{1}$ There are three main categories based on their composition: trichobezoar, formed from ingested hair, pharmacobezoar, consisting of accumulated undigested drugs, and phytobezoar, formed from nondigestible plant material. ${ }^{2}$ Bezoar causing bowel obstruction have been reported since the late 18 th century and most cases reported in the literature refer to bezoars of plant fibers formed in the stomach, which fragment and migrate to obstruct within the ileum and jejunum. ${ }^{1-3}$

Two previous reports of small bowel obstruction related to ingested bone exist.

Bandyopadhyay et al reported the case of a 66-year-old man who developed small bowel obstruction secondary to extensive adhesions resulting from trauma induced by the traversing of ingested pork bone. ${ }^{1}$ Mahendrayogam and others reported acute small bowel obstruction due to impacted bone in a 71-year-old man with a history of three previous laparotomies and extensive adhesions. ${ }^{2}$ To the best of our knowledge, this article is the first to report impacted bone as the sole cause of bowel obstruction in a patient free of previ-
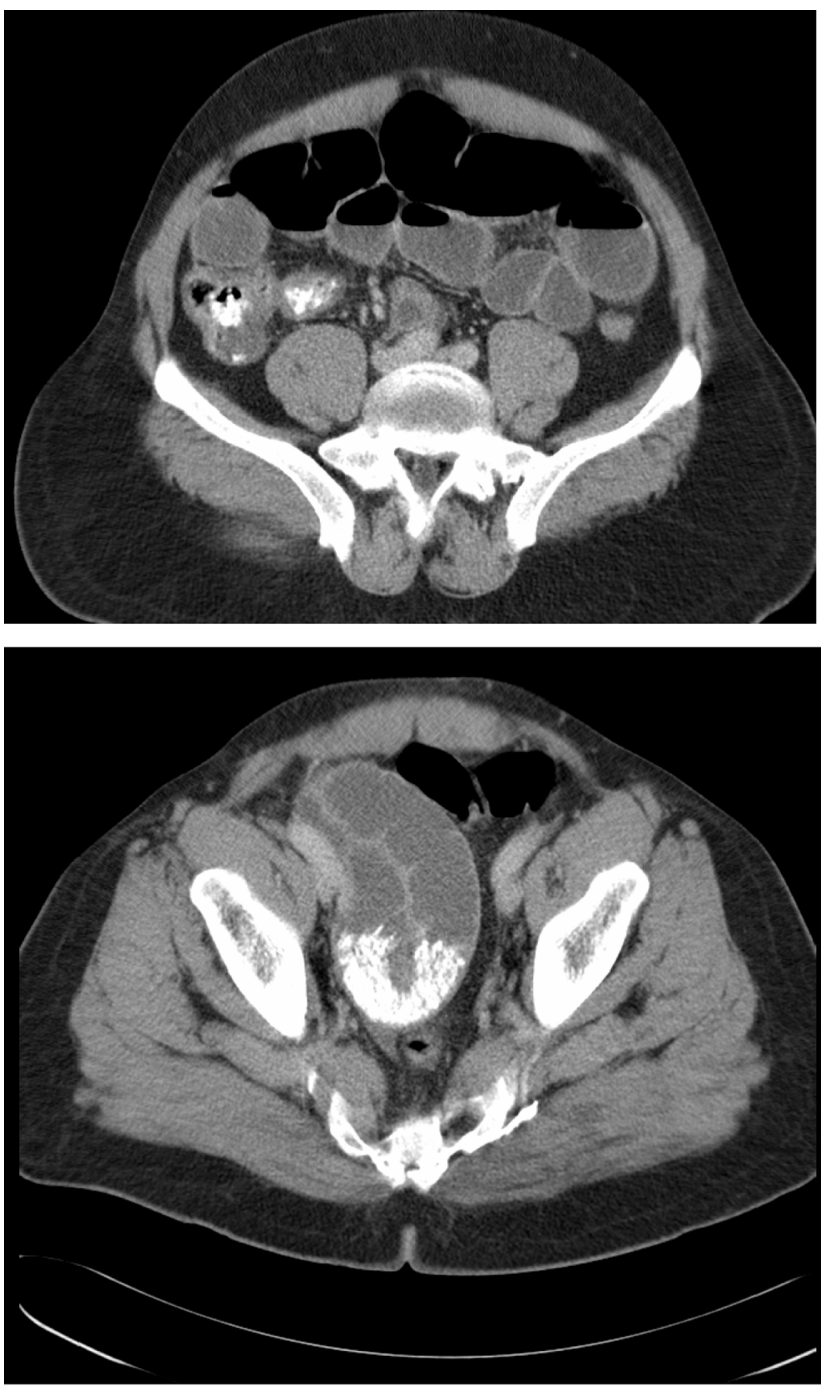

Figure 2 Two intravenous, contrast-enhanced CT axial images of the abdomen and pelvis demonstrating multiple dilated gas- and fluid-filled small bowel loops with high-density undigested bone material in the terminal ileum and cecum.

Abbreviation: CT, computed tomography.

ous surgery, adhesions, and predisposing bowel conditions such as diverticular disease or hernia.

Akhtar et al noted that alcoholics, psychiatric patients, denture wearers, rapid eaters, and those with insatiable appetites may be at greatest risk of unwittingly ingesting chicken bone. Furthermore, those with previous bowel pathology are most at risk of succumbing to complications from it. ${ }^{4}$

The literature recommends conservative treatment for all bezoars in the stomach and esophagus. Other treatment modalities include endoscopic removal, pulverization with laser, extracorporeal shock wave lithotripsy, or chemical dissolution. ${ }^{5}$ However, bezoars causing acute intestinal obstruction require surgical intervention. ${ }^{1,3}$ The use of laparoscopy in the management of acute small bowel obstruction is on the increase. In their systematic review of adult studies 
published over the last 20 years, O'Connor et al reported a conversion rate from laparoscopy to midline laparotomy of $29 \% .^{5}$ They concluded that bowel resection, unexpected pathology, and dense adhesion were the most common reasons for conversion to open surgery. Bezoar-induced bowel obstruction is an uncommon emergency and preoperative diagnosis is notoriously difficult. Further evidence is therefore required to make sound conclusions regarding the safety and effectiveness of laparoscopy in the management of bezoar-induced bowel obstruction.

CT imaging of the abdomen is considered most useful in attempting to identify the site of the obstructing bezoar and its complications. ${ }^{1}$

\section{Conclusion}

This case serves as a useful clinical reminder that recent dietary history may confer clues to the etiology of a patient presenting with acute intestinal obstruction in a virgin abdomen.

\section{Disclosure}

The authors report no conflicts of interest in this work.

\section{References}

1. Bandyopadhyay D, Orgles CS, Dewar EP. Small bowel obstruction due to inflammation secondary to ingested bone. Emerg Radiol. 2005;11: 381-385.

2. Mahendrayogam V, Sebastian BJ, Senior E, Keeling N. Acute small bowel obstruction due to impacted bone: a case report. BMJ Case Rep. Epub 2009 Mar 5.

3. de Groot B, Puylaert JB. Diospyrobezoar: an uncommon cause of obstructive ileus. Int J Emerg Med. 2008;1:333-334.

4. Akhtar S, McElvanna N, Gardiner KR, Irwin ST. Bowel perforation caused by swallowed chicken bones - a case series. Ulster Med J. 2007; 76:37-38

5. O'Connor DB, Winter DC. The role of laparoscopy in the management of acute small-bowel obstruction: a review of over 2,000 cases. Surg Endosc. 2012;26:12-17.

\section{Publish your work in this journal}

The International Medical Case Reports Journal is an international, peer-reviewed open-access journal publishing original case reports from all medical specialties. Previously unpublished medical posters are also accepted relating to any area of clinical or preclinical science. Submissions should not normally exceed 2,000 words or
4 published pages including figures, diagrams and references. The manuscript management system is completely online and includes a very quick and fair peer-review system, which is all easy to use. Visit http://www.dovepress.com/testimonials.php to read real quotes from published authors. 